\title{
Establishing an ambulance dispatch system for intrahospital transfers in a large teaching hospital in India
}

\author{
Prakash Swaminathan ${ }^{* 1}$, Kshitija Singh ${ }^{1}$, Angel Rajan Singh ${ }^{1}$, Devender Kumar Sharma ${ }^{2}$ \\ ${ }^{1}$ Department of Hospital Administration, AlIMS, New Delhi, India \\ ${ }^{2}$ AlIMS, New Delhi, India
}

Received: September 7, 2021

Accepted: October 11, 2021

Online Published: October 19, 2021

DOI: $10.5430 /$ jha.v10n5p11

URL: https://doi.org/10.5430/jha.v10n5p11

\begin{abstract}
During the Covid Pandemic, a lot of structural and process changes had to be made in a quick time in almost all the hospitals to accommodate the patients and admit them with the least exposure to the Hospital Staff and the bystanders of the patients. AIIMS Hospital in New Delhi India is a premier tertiary care teaching hospital, which is spread out in different areas. Two Hospital centers of AIIMS were designated as COVID Hospitals. Since there was no previous experience of intrahospital transfers of this magnitude, the hospital had to face lots of difficulties in such transfers and this translated into increased turnaround time. This paper concentrates on the mechanisms in which the Department of Hospital Administration found out the various issues plaguing this process. Later by Change Management, an Intervention was brought in, which helped in the framing of a standard operating procedure that helped in the easy transfer of the patients which was hassle-free and which continued to the second wave of the COVID pandemic.
\end{abstract}

Key Words: COVID, Pandemic, Ambulance, Change management, Operations, Offload time, Standard operating procedure

\section{INTRODUCTION}

AIIMS is the premium research and teaching institute with existing bed strength of 2,478 beds. It is widely spread into five locations and has eight specialty centers spread across the premises, the newest being NCI (National Cancer Institute) at Jhajjar Haryana. The main hospital of AIIMS is spread on an area of about 100 acres and the latest center of AIIMS, AIIMS-NCI in an area of about 300 acres at a distance of about $34 \mathrm{~km}$ from Main AIIMS Hospital. AIIMS being a super-specialty tertiary care institute primarily caters to referred patients and therefore, as a matter of policy of the institute, ambulance services until recently had a lim- ited scope; of pre-identified intrahospital transportation and transportation of sick patients within various centers of AIIMS. The well-equipped ambulances were manned by EMTs (Emergency Medical Technicians - who were technically qualified - who were in possession of Advanced Life support certificate) and they accompanied only critical patients. However, in the recent COVID pandemic, the scope and role of ambulance services have witnessed their remarkable participation in patient care management.

With the pandemic hitting India, AIIMS New Delhi took up the responsibility of not only preparing treatment protocols and research but also extensively prepared futuristically India.

Published by Sciedu Press 
for an upsurge in the number of patients requiring isolation facilities. Keeping in mind the NCI, Jhajjar campus was operationally restructured for COVID patients along with JPNATC (Jai Prakash Narayan Apex Trauma Center). Along with other operational challenges, the most important was shifting COVID patients to the designated centers. Main Hospital of AIIMS became the center where all patients would arrive, would be triaged and tested and if detected positive for COVID, would be transferred by ambulance to NCI-Jhajjar covering a distance of about $34 \mathrm{~km}$ in about one hour (in case of yellow and green triaged patients) and to JPNATC (in case of Red triaged patients) covering a distance of $2 \mathrm{~km}$ in about 5-10 minutes. There is a dedicated underpass route connecting the main AIIMS campus and the JPNATC and hence traffic jam is not a constraint.

No new routes were planned. These were the existing routes through which prior transfers took place, but never to the magnitude as it was taking place during COVID.

When COVID started taking the shape of an epidemic, there were various discussions of how to manage these patients in AIIMS. We had to help prevent the spread of the disease, as a tertiary hospital of this magnitude where all kinds of patients who were being treated from the most common to the rarest of the rare diseases merge in, would itself act as a big source of spread. It was very difficult to decide on closing one center completely and converting it into a COVID Centre, as it would discontinue the treatments of the patients of that specialty, thereby causing indirect harm to these patients. After many deliberations, hence, it was decided to convert the NCI -Jhajjar to a COVID center as it was a new center that had recently come up and so the entire paraphernalia of this hospital could be shifted for this pandemic. The second decision was to convert the existing JPNATC - the trauma center of AIIMS, as it would have conveniently given us $250+$ beds, was isolated and away from the crowd of Main AIIMS hospital and at the same time, near to the AIIMS hospital. Patients from this hospital could easily be accommodated in various beds in Main AIIMS in the departments of Orthopedics, Surgery, and Neurosurgery. Though this lead to reducing the existing number of beds for these fields and sharing their beds with trauma patients, the administration had to take up this decision as we were going to face a bigger war of the pandemic.

Transportation plays an important aide in the treatment of the patient irrespective of the size, and sophistication of the hospital. A lot of protocols and standard operating procedure's (SOP) already existed for intrahospital transportation of sick patients, either from emergency to Wards/ICUs or from wards to ICUs or for radiological procedures like CT/MRI. But transportation of COVID patients between the facilities in ambulances lacked literature on guidelines. There are many studies to show that Ambulance Offload delay is a performance benchmark to ensure quality patient care. ${ }^{[1]}$ Many researchers have used the Markovian queueing model for Ambulance offload delays. ${ }^{[2,3]}$

The transportation of COVID patients required designated transportation facility and area, the safety of health care workers accompanying the patient, the safety of bystanders, safe transportation of patients with readiness to deal with medical contingency en-route and post transportation decontamination.

To begin with, a designated route was identified for shifting patients from the screening wards to the elevator and identified ambulance bay. The ambulance was sent from the COVID facility and an OTA (Operation Theater Assistant) would accompany to take the patient found positive from COVID screening wards of the main building. The administrative duty officers were assigned the responsibility of coordinating the transfer between the centers. However, after few days various challenges were brought to notice. The study aims at identifying these challenges and how various interventions were implemented, thereby improving the system and thus reducing the hassles. These interventions by way of various discussions were then put forth into a SOP, which improved the system so well that the system started functioning on an auto mode.

\section{Need for the study}

A serious need was felt in mapping the existing processes as there was a lot of time delay in the ambulance dispatch of the referred patients. This lead to precious time being wasted, as the patients waited for long hours in the casualty department despite being diagnosed as COVID Positive as no decision was clear regarding their destination to which of the centers of AIIMS and as to what would their modes of transfer be. Also, there were no clear standing instructions as to who would monitor the movement of these patients, who would accompany them, etc. Also, the increased time being spent in the casualty by such COVID-positive patients was a risk to the other doubtful cases or other cases awaiting treatment and their attendants. Hence a system had to be evolved wherein there would be a faster dispatch of these patients to the COVID Hospitals

\section{METHOD OF STUDY}

(1) A study was conducted to delineate what are the reasons for the delay in the transfer of the patients.

The entire process mapping of the existing transfer processes was studied in detail. A brainstorming session was held to 
find out the lacunae in the system and the causes of the delay in the shifting of the patients. Once the problem statement was charted out, the reasons given by the various stakeholders were quantified to see what the major causes of the increased offload time were.

(2) Trying to find out possible solutions and interventions to correct the deficiencies to correct the existing problems was the next step.

Once the problems were delineated and recognized, each of these problems was put in for discussion, and solutions were formulated. These solutions were then deliberated upon and a decision was made regarding the best solution for all of these problems. Since it is not good to work on these issues in parts, all these solutions were then put together and a model formed which was tested for two to three days as a dry run model. Gaps were found out and the same were corrected till a foolproof system evolved. Mock runs of the ambulances were made and role-playing helped a lot, to find out a framework to implement the interventions.

(3) To map out an SOP that can be followed by all, thereby reducing the main problem of the time and transit for the transfers.

After all these deliberations and simulation exercises and decision making, an SOP was formed and sent to the clinical heads for their inputs and observations. A final SOP then formed was circulated for effective implementation.

(4) After the implementation of the interventions, feedback was taken from the stakeholders regarding the deficiencies if any and if there was any improvement in the system.

\section{ObServation \& Results}

(1) A detailed study was conducted to find out as to what was the existing way in which patients reporting to the emergency were being transferred. It was found out that, in the emergency as and when a COVID positive patient comes in, he is triaged into red, green, and yellow. Red patients are moved into the Red observation area in the emergency and wherein they are stabilized before they were moved to JPNATC, where the red triaged / employees of AIIMS patients were generally kept.

As and when the yellow and green triaged patients were stabilized, an ambulance was arranged by the duty officers (Administrative doctors manning the control room ).

In both cases, the Duty officers had to make arrangements for the ambulances, keep a track of the various ambulances, make arrangements of ambulances from the JPNATC and NCI in coordination with the duty officers of JPNATC and

Published by Sciedu Press
NCI. At the same time, they had to coordinate with the Doctors, faculty, the OT technician, etc to make arrangements during the transfer. Since the ambulances from different centers of AIIMS were being used it required a lot of coordination.

This was a new operational commitment that required good precision and coordination with multiple places and people and hence this was already eating into the time of a heavily working duty officer adding to the existing chaos of running the administration of a tertiary care medical institute.

Our study showed that most of the time was lost in coordinating the ambulances from different places, coordinating as to who the accompanying doctor/paramedic would be, and difficulties when the patient was not accepted in time at the destination hospital.

Though no records regarding the time were kept, as a study in this regard was not planned, the duty officers at all the places felt that the ambulances took about half an hour to even three hours in transferring patients to JPNATC, a hospital which was hardly less than $1 \mathrm{~km}$ distance from the emergency of AIIMS.

As NCI catered to stable yellow to green and green triaged patients, the transition of the patients was smooth, but with occasional hurdles. The ambulances detailed to go to NCI had to also carry patients from Dr. Ram Manohar Lohia Hospital, Lady Hardinge Medical College and Hospital and soldiers serving in the Paramilitary Organizations and who needed indoor admissions. These were some examples of interhospital transfers which had to be modeled after a successful intratransfer model achieved for patients.

Also, patients who were detected negative had to be brought to AIIMS Hospital for treatment. Safety of staff and timely transportation was an important mandate.

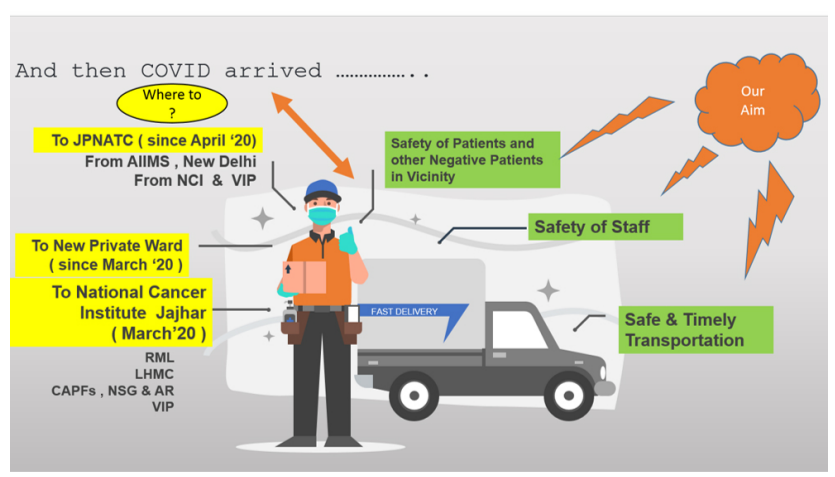

Figure 1. Figure 1 shows the hospitals from which patients were transferred and their destination. It also shows the aim which we had in our mind during our transfers 
(2) All these problems led to brainstorming within the administration. The duty officers of the department of hospital administration largely responsible for transportation coordination were interviewed through an unstructured questionnaire to find the challenges faced by them and look for solutions.

They were asked to enumerate the reasons for the causes of the delay of the transfer of the patients. The reasons obtained were then drawn in the form of a fishbone (Ishikawa cause and effect chart). The data obtained are shown in Figure 2 below.

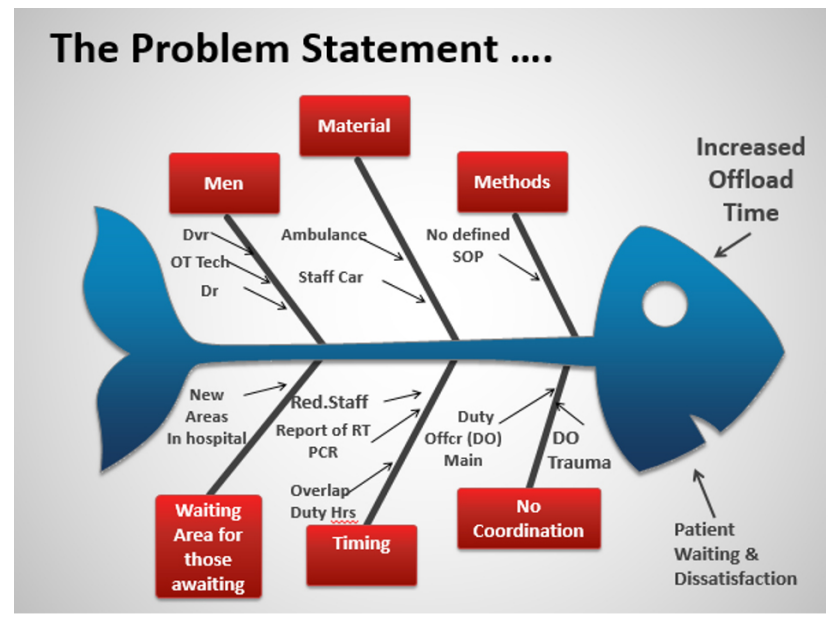

Figure 2. A fishbone diagram showing the cause of delay in Offload time of patients

The reasons which were enumerated were then quantified As per data obtained, the break up of the reasons are as follows as shown in Figure 3.

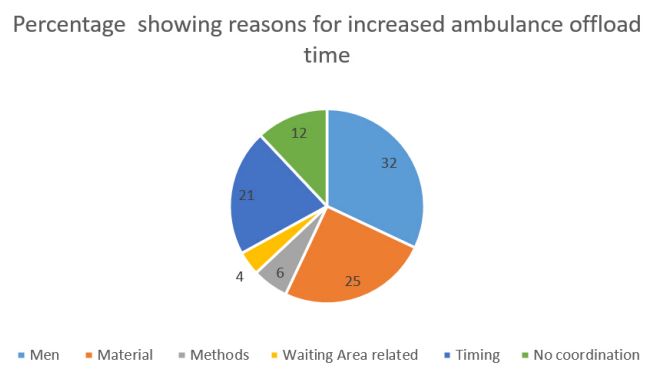

Figure 3. Pie Chart showing the various causes of the delay as per the Fishbone diagram

\subsection{Analysis of the problem}

(1) The delay in ambulance arrival (sometimes exceeding three hours) from COVID centers for patient shifting was because there was a delay in getting a doctor, OT technician, or driver for shifting of the patient.
(2) There was a lack of any SOP for shifting of a patient and a lack of shifting team/Transportation team to facilitate the transfer of patients.

(3) The resident doctors from the parent unit were called and made to don and doff for each shifting which compromised care of patients in peripheral areas and wastage of PPEs.

(4) The shifting out of patients from the ambulance to COVID centers was often delayed due to lack of staff and poor coordination at receiving center, often causing deterioration of the patient condition, and sentinel event of a patient crashing was also noted.

(5) Occasionally there were instances as patients (especially stable ) and their attendants would be waiting at different places in the hospital and tracing them for transfer would become difficult.

(6) Since the cars and ambulances of different places were under different areas of command, there was a delay in transportation as a lot of time was involved in coordinating for the same.

(7) The duty officers at the three hospitals were already overworked with the existing workload of a tertiary hospital. The pandemic of COVID only added to it. Some of the doctors themselves were either tested positive or were in quarantine. So there was no way to augment the already worked-up duty officers.

(8) Most of the delays took place at night during which there were delays in getting the PCR report, there were no overlapping of duty hours of different cadres which caused lots of absence of the workers during these changeover of staff as they were in either in the process of donning or doffing.

An intervention was done in the existing transportation process and the turnaround time of ambulances was monitored.

\subsection{The intervention}

A transportation team was formed along with an ADC (Ambulance dispatch Centre): It was decided that the transportation of the ambulance would be headed by the transportation in charge and supervised by an officer on duty.

Pooling of ambulances from Main Hospital and Trauma Centre was done.

A faculty on call for the COVID center was identified with whom the parent department of the COVID screening ward would coordinate about the clinical condition of the patient. The faculty on-call would then allot a bed at the COVID center depending on the severity of clinical status. The parent department then informed the officer on duty at Main Control Room about the need to transfer and the bed allotted. The duty officer then informed the ambulance coordinator about the same. 
An ambulance coordinator was stationed at the ADC round the clock. He would manage the ambulance staff, coordinate the dispatch of the ambulances, decide the route of the ambulance, coordinate with the parent department and COVID center and intimate the COVID center duty officers well before time to prepare to receive the patients.

The ambulances were tracked through a GPS to strictly monitor the TAT (Turn Around Time).

The duty officers at COVID centers who manned the office round the class kept the transportation staff ready to avoid any delay in shifting out of patients from an ambulance to a pre-identified patient care area.

As per the policy only the ventilator patients were accompanied by the doctor. The ambulance coordinator coordinated with the COVID screening ward and when the ambulance and patient were both ready, the doctor of the COVID screening ward along with EMT and transportation support staff were asked to wear PPE. The security was informed to clear the passage and corridors and the COVID lift was kept ready to decrease the nosocomial spread of infection and safeguard the bystanders.

The ambulance staff would also disinfect the ambulance after its return.

An SOP was issued based on these above-mentioned interventions and the Turn around time (TAT) was drastically reduced.

\subsection{The SOP}

(1) All the ambulances were brought under the direct control of the Main Hospital. An ambulance dispatch center was created and it was the responsibility of the ambulance dispatch center to ensure that to and from transfers from any of the hospitals of AIIMS and other hospitals will be entirely coordinated by this center.

(2) The emergency medical technicians who were contractual and had good service in AIIMS were upgraded to the post of ambulance coordinator EMT with an enhancement of their pay. . He became a supervisor amongst his equals.

(3) More number of EMTs were recruited so that there could be hassle-free transfers accompanied by a paramedic and who would not be involved in other areas of the hospital. All ambulances transferring COVID patients shall be accompanied by an EMT who will be formally trained in basic life support skills. It shall be the decision of the transferring area to decide whether the patient is safe to be transferred with EMT alone or a doctor is required to be sent along with in the ambulance. However, no patient on ventilator/NIV/Inotropes/HFNC/etc. shall be transferred without an

Published by Sciedu Press appropriate resident doctor accompanying the said patient.

(4) Ambulance shall be called for by transferring area only when the receiving area has accepted the request to transfer, the transfer summary of the patient is ready and the resident doctor if required to accompany the patient $\&$ respective area's hospital attendant/s to transfer the patient till the ambulance are readily available. The accompanying doctor (if required) \& hospital attendant/s may kindly don their PPE's only after getting confirmation regarding the availability of the ambulance in the next half hour by the Ambulance Coordinator. Transfer of COVID-positive patients from non-COVID areas will be prioritized.

(5) The arrival of Ambulance along with EMT at the nearest possible location will be informed to the transferring area by the Ambulance Coordinator or EMT. It shall be the responsibility of the transferring area to shift the patient to the ambulance within a maximum of 15 minutes of the arrival of the ambulance failing which the ambulance may initiate another transfer and the current transfer will be put last in the transfer queue and a fresh transfer time estimate shall be provided.

(6) Duty Officer in JPNATC/NCI/other areas shall ensure patients are accepted therein $24 \times 7$ once the transfer has been approved. It shall be the responsibility of the receiving areas (JPNATC/NCI/others) to arrange for adequate numbers of stretchers, hospital attendants, filled oxygen cylinders, etc. to transfer patients from the ambulance to the designated beds. As multiple stable patients may be shifted in an Ambulance, to facilitate quick turnaround of ambulances, a holding area for stable patients maybe be created within JPNATC/NCI pending their screening and assessment. For all patients with enhanced ventilation requirements, the Duty Officer in JPNATC/NCI will in consultation with the clinical team ensure that the said patient is taken up in the designated bed without any delay. However, in either case, the Ambulance must turn around from the receiving areas (JPNATC/NCI/others) within a maximum of 15 minutes of its arrival. Head, Medical Management Team(s) in JPNATC/NCI may consider assigning dedicated personnel to assist their Duty Officers in seamless ambulance transfers and ensure quick turnaround of ambulances.

(7) In cases where only EMT is accompanying the patient, handover will be taken by JPNATC/NCI teams at ambulance reception itself and the ambulance with EMT will be freed as soon as the patient is shifted to the holding area in JPNATC. In cases where a resident doctor is accompanying the patient, the resident doctor will give handover to the clinical team in JPNATC and shall be dropped back to his respective area after doffing in the JPNATC staff car which 
will be provided by the JPNATC Duty Officer. In such cases, the ambulance with EMT will not wait for patient handover and return as soon as a patient is shifted onto the JPNATC/NCI stretcher trolley, to be available for the next call. Portable Monitor/Ventilator if any taken along with such patients can be sent back by the JPNATC Duty Officer in the next trip of the ambulance for return to respective areas.

Five of the Emergency Medical Technician who had performed very well, during the periods of Pre Covid, were upgraded to EMT - Supervisor, which made them eligible for higher of managing and coordinating the transfer of the patients between the ED and the different departments.

\subsection{Post-intervention}

There was significant improvement once the intervention was brought streamlined. Feedback from the duty officer was again taken through an unstructured interview and comprised of following:

(1) The TAT was drastically reduced. The SOP helped in streamlining the processes.

(2) Increase in the number of transfers.

(3) The hospital helped other health facilities and hospitals with transportation.

(4) The doctors from in-patient wards were not pulled out and did not have to compromise patient care.

(5) Zero patients deteriorated during transfer.

(6) Decreased complaints of waiting from both ends (The main hospital sending the patients and COVID centers receiving the patients).

(7) Decrease in PPE wastage as no extra person apart from transportation team had to wear new PPE and doff.

(8) The vehicles were fitted with GPS tracking which could be tracked by the duty officers. This way intervention by the duty officers took place as and when required. Once the system started rolling in, after certain toothing issues to accept the sudden change management brought in, it was a smooth transition. In fact, during the second wave of COVID, this hospital never had any issues regarding the intrahospital transfers either for treatment or for investigations.

\section{Discussion}

When this problem was observed, we saw that many of the employees of the hospitals themselves were sufferers. The employees themselves or their relatives themselves found themselves at the receiving end when intrahospital transfers which were hardly a few minutes away took about two hours.
Hence using the ADKAR Model the Department of Hospital Administration brought Change management. ${ }^{[4]}$ Once the employees themselves appreciated the problems and the solutions as proposed, implementing the SOP was not very difficult. Quality improvement, troubleshooting, and incident tracking were the main aims of the Ambulance dispatch center (ADC) ${ }^{[5]}$

Using GPS systems in the ambulances, we could track the movement of the ambulances. Thus the control room duty officers acted only on a case-to-case basis as and when the offloading time was increasing beyond the stipulated 15 minutes. This is how technology helped in the tracking of the movement of the ambulances ${ }^{[6]}$ The offload time in our case was different. We were not bringing patients into the casualty. There is much literature available on this concept. Ours was more of an intrahospital transfer in a tertiary hospital. This warranted us to be more cautious here there was a secondary response time that was involved. The patient had already been attended to once in the hospital. We now needed to relocate him. Hence, taking references from various studies like the Zhen et al. ${ }^{[7]}$ and the Van Barneveld et al., ${ }^{[8]}$ we too followed the same heuristic model wherein the ambulances were relocated than coming back to their bases. This helped us in saving a lot of time. ${ }^{[9]}$

Motivation plays an important role in organizational change. A small reward for the well-performing employees by giving them a pay hike and an elevated designation of EMT supervisors ensured that they supervised the movement of the patient traffic well and the same was coordinated seamlessly. ${ }^{[10-12]}$

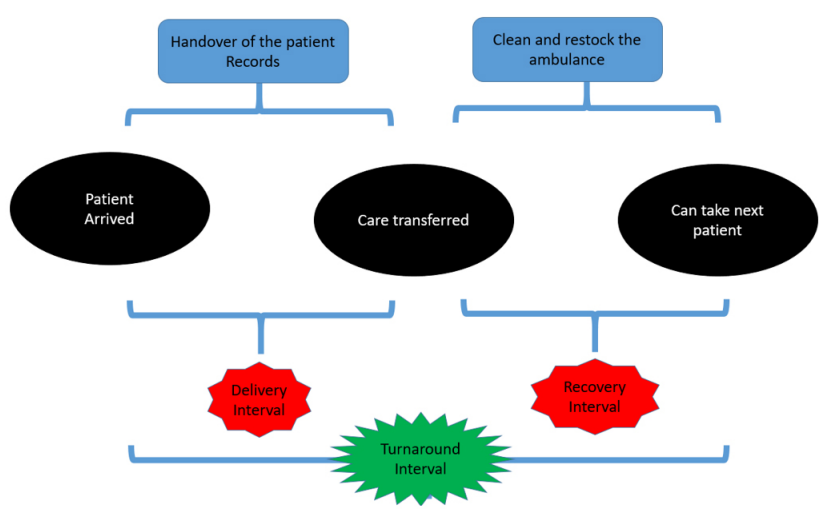

Figure 4. The Turnaround Interval and what it comprises of

We noticed that the important problem which we were facing was that the ambulances and the personnel were posted in different centers and under different command structures. Since the main objective was that the COVID-19 patients needed the best treatment, all the hospitals catering for the same were brought under one command and control, following the 
Fayols principles of management, Unity in Command. ${ }^{[13,14]}$

Our main aim was to decrease both the delivery interval and the recovery interval (see Figure 4) of an ambulance and thus increase productivity. ${ }^{[1]}$

Proper handover and communication was also ensured as that forms an important point in the continuity of the treatment. ${ }^{[13]}$

Thus this hospital brought about a change in the operations by studying the existing process, bringing in a change, motivating the personnel, and thus bringing about a change by bringing in an SOP after consultation of all involved, using the various principles of management and in a time-bound manner.

\section{Conclusions}

When the first wave of COVID hit India, all hospitals, including the tertiary hospital like ours were trying various methods to treat and control the pandemic. Many operational issues like the one took place, which when studied in detail came out with good outcomes and improved patient satisfaction. The processes became so ingrained that during the second wave, all these processes took place at a spinal level and were absorbed into the operations system of this hospital.

\section{ETHics Statement}

No patient data has been retrieved or shared.

\section{CONFlicts of InTEREST Disclosure}

The authors declare they have no conflicts of interest.

\section{REFERENCES}

[1] Li M, Vanberkel P, Carter AJE. A review on ambulance offload delay literature. Health Care Manag Sci. 2019; 22(4): 658-75. PMid: 29982911. https://doi.org/10.1007/s10729-018-9450-x

[2] Almehdawe E, Jewkes B, He QM. A Markovian queueing model for ambulance offload delays. Eur J Oper Res [Internet]. 2013; 226(3): 602-14. https://doi.org/10.1016/j.ejor.2012.11.030

[3] Jagtenberg CJ, Bhulai S, van der Mei RD. Dynamic ambulance dispatching: is the closest-idle policy always optimal? Health Care Manag Sci [Internet]. 2017; 20(4): 517-31. PMid: 27206518. https://doi.org/10.1007/s10729-016-9368-0

[4] Augustin M, Schommers P, Suárez I, et al. Rapid response infrastructure for pandemic preparedness in a tertiary care hospital: Lessons learned from the COVID-19 outbreak in Cologne, Germany, February to March 2020. Eurosurveillance. 2020; 25(21): 1-7. PMid: 32489176. https://doi.org/10.2807/1560-7917. ES.2020.25.21.2000531

[5] Mould-Millman NK, De Vries S, Stein C, et al. Developing emergency medical dispatch systems in Africa - Recommendations of the African Federation for Emergency Medicine/International Academies of Emergency Dispatch Working Group. African J Emerg Med [Internet]. 2015; 5(3): 141-7. https://doi.org/10.1016/j.afje m.2015.06.005

[6] Khalique V, Shaikh S, Dass M, et al. Automatic Ambulance Dispatch System via One-Click Smartphone Application. Indian J Sci Technol. 2017; 10(36): 1-9. https://doi.org/10.17485/ijst/2017/v $10 i 36 / 119178$

[7] Zhen L, Wang $\mathrm{K}, \mathrm{Hu} \mathrm{H}$, et al. A simulation optimization framework for ambulance deployment and relocation problems. Com- put Ind Eng [Internet]. 2014; 72(1): 12-23. Available from: http: //dx.doi.org/10.1016/j.cie.2014.03.008

[8] Van Barneveld TC, Bhulai S, Van Der Mei RD. The effect of ambulance relocations on the performance of ambulance service providers. Eur J Oper Res. 2016; 252(1): 257-69.

[9] Carvalho AS, Captivo ME, Marques I. Integrating the ambulance dispatching and relocation problems to maximize system's preparedness. Eur J Oper Res [Internet]. 2020; 283(3): 1064-80. https: //doi.org/10.1016/j.ejor.2019.11.056

[10] Shoraj D, Llaci S. Motivation and Its Impact on Organizational Effectiveness in Albanian Businesses. SAGE Open. 2015; 5(2). https://doi.org/10.1177/2158244015582229

[11] Sabir A. Motivation: Outstanding Way to Promote Productivity in Employees. Am J Manag Sci Eng. 2017; 2(3): 35. https: //doi.org/10.11648/j.ajmse.20170203.11

[12] Deressa AT, Zeru G. Work motivation and its effects on organizational performance: The case of nurses in Hawassa public and private hospitals: Mixed method study approach. BMC Res Notes [Internet]. 2019; 12(1): 1-6. PMid: 30961666. https ://doi.org/10.1186/ s13104-019-4255-7

[13] Bacud SAD. Henri fayol's principles of management and its effect to organizational leadership and governance. J Crit Rev. 2020; 7(11) 162-7. https://doi.org/10.31838/jcr.07.11.25

[14] Marume SBM, Jubenkanda RR. The Basic Concepts and Principles of Unity of Command and the Span of Control. Int J Bus Manag Invent ISSN [Internet]. 2016; 5(6): 14-8. Available from: www. ijbmi.org

[15] Bost N, Crilly J, Wallis M, et al. Clinical handover of patients arriving by ambulance to the emergency department - A literature review. Int Emerg Nurs [Internet]. 2010; 18(4): 210-20. PMid: 20869662. https://doi.org/10.1016/j.ienj.2009.11.006 